\title{
Effect of applying centering pregnancy model versus individual prenatal care on certain prenatal care outcomes
}

\author{
Tyseer Marzouk*1, Inas Mohamed Abd-Allah ${ }^{2}$, Hend Shalaby ${ }^{3}$ \\ ${ }^{1}$ Woman's Health and Midwifery Nursing, Faculty of Nursing, Mansoura University, Egypt \\ ${ }^{2}$ Maternity, Obstetrics and Gynecology Nursing, Faculty of Nursing, Suez Canal University, Egypt \\ ${ }^{3}$ Obstetrics and Gynaecology, Faculty of Medicine, Mansoura University, Egypt
}

Received: March 14, 2018

Accepted: May 9, 2018

Online Published: May 16, 2018

DOI: $10.5430 /$ cns.v6n2p91

URL: https://doi.org/10.5430/cns.v6n2p91

\begin{abstract}
Objective: This study aimed to compare effect of applying centering pregnancy model (CPM) versus individual prenatal care on certain prenatal care outcomes.

Methods: A quasi experimental research design was followed. A purposive sample of 216 pregnant women without medical or obstetric problems requiring individualized care, was recruited from the Antenatal Outpatient Clinics of Mansoura University Hospitals, Egypt. Participants were randomly assigned to receive prenatal care under CPM or individual prenatal approach. Data were collected for the healthy behaviors adoption using Pregnancy-relevant Health Behaviors scale, women's extent of troubling about pregnancy physical discomforts using a Pregnancy Symptoms Distress scale, and women's satisfaction with prenatal care using Patient Participation \& Satisfaction Questionnaire.

Results: Post-intervention, CPM group equated to individual care group experienced lower distress about experienced pregnancy physical discomforts ( $8.06 \pm 2.40$ vs. $15.42 \pm 3.84$ respectively; $t=16.89 \& p<.001)$, reported higher engagement to pregnancyrelevant health behaviors ( $37.71 \pm 2.91$ vs. $29.78 \pm 4.3$ respectively; $t=15.59 \& p<.001)$, and higher satisfaction with and participation in care $(80.8 \pm 10.4$ and $63.8 \pm 11.1$ respectively, $t=11.62 \& p<.001)$.

Conclusions: Hypotheses of the current study were accepted where CPM of prenatal care was associated with increased women adoption to the pregnancy-relevant healthy behaviors, reduced women distress about the experienced pregnancy physical discomforts and increased women participation and satisfaction about prenatal care.
\end{abstract}

Key Words: Centering pregnancy model, Individual prenatal care, Pregnancy-relevant healthy behaviors, Physical discomforts, Prenatal care outcomes

\section{INTRODUCTION}

Pregnancy is a time of physiological changes and emotional variations. It is a time of uncertainty and anticipation for birth and thought about parenting. Pregnant women tend to liken notes with others as pregnancy advances and be likely to share reactions with their mates. ${ }^{[1,2]}$ Most clinical sites in Egypt provide antenatal care in individual approach. In this approach, caregivers are pressured to check up large numbers of clients in a limited time, making clients to be dissatisfied with the short time spend in receiving care after long waiting.

\footnotetext{
*Correspondence: Tyseer Marzouk; Email: tm_fathy@yahoo.com; Address: Woman’s Health and Midwifery Nursing, Faculty of Nursing, Mansoura University, Egypt. 
In a previous national study, individual care was criticized by prolonged waiting time, lack of continuity of caregivers, and lack of social and psychological support. ${ }^{[3]}$

Centering pregnancy the innovative model of prenatal care, seems to close the gap between what is actually provided and looked for. In centering pregnancy model (CPM) of care components of antenatal care, health assessment, education and skills development, are provided in an integrated approach. In the CPM, care is provided at a group setting to 8-12 pregnant women; with similar due month of delivery along with guest speakers (i.e., family member or a friend who has a previous experience of rearing children). ${ }^{[4]}$

The premise of CPM is that learning and support are enriched by drawing on group resources; knowledge, ideas, and experiences of same group members and their experienced guest speakers. Gathering in a group setting with other pregnant women at the same gestation age who are sharing physiological changes of pregnancy, fosters supportive relationships, provide social interaction, and helps to change woman's perception of pregnancy concerns. ${ }^{[5]}$ Moreover, expectant mothers' empowerment is improved by taking a vital role in self-care. Where each group member actively participate in health assessment by taking blood pressure, weighing themselves, and testing their urine for glucose and ketones. $^{[6]}$

A previous randomized controlled clinical trial had found pregnant women sharing group prenatal sessions, were less likely to have suboptimal prenatal care and more likely to have increased satisfaction with the received care. ${ }^{[7]} \mathrm{Com}-$ panions attendance was accounted as an important factor for satisfaction. The CPM members appreciated the opportunity and time to exchange experiences with same group members and the group facilitator. ${ }^{[8]}$ Moreover, healthier weight trajectories; less weight gained during pregnancy and more weight lost postpartum, beside a reduction in babies born small for gestation age were observed among women received group prenatal care. ${ }^{[9,10]}$

\subsection{Significance of the study}

Lack of social and psychological support in antenatal care was perceived by $56.1 \%$ of the pregnant women and $86.3 \%$ perceived that the individual prenatal care is not apt familial participation in care. ${ }^{[3]}$ Despite that, this model of prenatal care still provided in most of the clinical sites. Given the evidence that aspects of social support enhance the women's and infant's health. The healthcare providers have to create opportunities for networks to support pregnant women. The current study is expected to find out CPM of care yields more positive prenatal outcomes among pregnant women. This result would encourage caregivers to adopt, encourage and utilize the CPM of care. Ultimately, this will reflect on a more healthy pregnancy outcome beside saving caregiver time and energy. Lastly but not least, increases pregnant women satisfaction. Therefore, the present study was aimed to compare effect of applying CPM versus individual prenatal care on certain prenatal care outcomes.

\subsection{Operational definitions}

\subsubsection{The centering pregnancy model of care}

The CPM was defined by Sharon Schindler Rising, ${ }^{[11]}$ as an innovative method to prenatal care by which care is provided by a midwife or an obstetrician in group setting. It is provided to groups of eight to 12 women of similar due month of delivery. Each group meets eight to ten times through the gestation period. Every session takes about 90 to 120 minutes. The "Essential Elements of Centering Pregnancy" include the following:

(1) Health assessment occurs within the group space.

(2) Women are involved in self-care activities.

(3) Stability of group leadership is required.

(4) A facilitative leadership style is used.

(5) Each session has an overall plan.

(6) Attention is given to core content; emphasis may vary.

(7) Group conduct honours the contribution of each member.

(8) The group is conducted in a circle and group size is optimal to promote the process.

(9) The composition of the group is stable but is not rigid.

(10) Involvement of family support people is optional.

(11) Group members are offered time to socialise.

(12) Evaluation of outcomes is ongoing.

\subsubsection{Prenatal care outcomes}

In this study, certain prenatal care outcomes were assessed; specifically, 1) maternal adoption to pregnancy-relevant healthy behaviors, 2) maternal distress about the pregnancy physical discomforts, and 3) maternal satisfaction with and participation in prenatal care model.

\subsubsection{Pregnancy-relevant healthy behaviors}

Indicate to the activities taken by the pregnant woman and affecting woman's and fetal health. ${ }^{[12]}$

\subsubsection{Maternal distress about the pregnancy physical dis- comforts}

Refers to the woman's level of distress from the minor discomforts experienced during pregnancy.

\subsection{Aim of the study}

This study aimed to compare effect of applying CPM versus individual prenatal care on certain prenatal care outcomes. 


\subsection{Hypotheses of the study}

Three research hypotheses were tested to fulfill aim of the present study.

Hypothesis 1: "Pregnant women who receive care under the CPM, engage in pregnancy-relevant healthy behaviors more than those who receive individual prenatal care".

Hypothesis 2: "Pregnant women who receive care under the CPM, report lower distress score about the pregnancy physical discomforts than those who receive individual prenatal care".

Hypothesis 3: "Pregnant women who receive care under the CPM, report higher participation in and satisfaction with the provided care than those who receive individual prenatal care".

\section{MeTHODS}

\subsection{Study design}

The present study was designed as a quasi-experimental. The intervention group followed the CPM of prenatal care, while the control group was subjected to the conventional individual prenatal care.

\subsection{Study setting}

The present study was conducted at the Antenatal Outpatient Clinics of Mansoura University Hospitals, Egypt. Along with an adjacent pre prepared room; with adequate number of seats, data show, and supportive materials (e.g., baby model, Flip-charts etc.).

\subsection{Sampling}

During the period from August 2016 to January 2017, a non-probability purposive sample of 216 pregnant women was recruited to share in this study. Inclusion criteria of the participants: All pregnant women were eligible to participate in this study if were: (1) Pregnant at or before 24 weeks of gestation. As, this is the time of the initial prenatal care visit and to be early assigned for a specific model of care and avoid sample contamination; if was already received a care model and assigned for another; (2) Free from any medical or Obstetric problems require individualized care (e.g., diabetes, pregnancy-induced hypertension), and (3) Can read and write; as tools of data collection were self-administered.

\subsubsection{Inclusion criterion of the companions}

Each participant was allowed to join one companion. There was a need for the companion to have a previous experience with labor and delivery and children rearing as an inclusion criterion. That is to ensure active participation in group discussions.

Published by Sciedu Press

\subsubsection{Sample size calculation}

Considering level of significance of $5 \%$, study power of $80 \%$, and by using the following formula: $\mathrm{n}=\left[(\mathrm{Z} \alpha / 2+\mathrm{Z} \beta)^{2} \times\right.$ $\left.(S D)^{2}\right] /$ (mean difference between the two groups) ${ }^{2}{ }^{[13]}$ the sample size was calculated. Where, $\mathrm{Z} \alpha / 2$ : depends on level of significance of $5 \%$, this is $1.96, \mathrm{Z} \beta$ : depends on study power of $80 \%$, this is $0.84, S D=$ standard deviation, and the mean difference between the two groups was 2.6; from a previous study proposed to compare effect of CPM versus individual prenatal care on prenatal care outcomes. ${ }^{[7]}$ Therefore, $\mathrm{n}=\left[(1.96+0.84)^{2} \times(6.8)^{2}\right] /(41.1-38.5)^{2}=107.3$ per each arm. Thus, 108 pregnant women were assigned for the CPM group and the same number was assigned for individual prenatal care group. As the dropout rate did not considered in the present sample size, the declined subjects were replaced.

\subsubsection{Recruitment and groups' assignment}

To recruit the study subjects, patients' records were reviewed for those firstly attend the clinic before or at 24 weeks gestation. Two hundred sixteen eligible pregnant women were identified and assigned to the intervention group or the control group. Participants of the intervention group $(n=108)$ were allocated into 12 subgroups. Each formed of 9 participants sharing same due month of delivery to be joined in future sessions. The flowchart of the studied sample is presented in Figure 1.

\subsection{Tools of data collection}

\subsubsection{Structured self-administered questionnaire}

The participant's general characteristics were collected using a structured questionnaire. It was developed by the researchers from six items (i.e., participant's age, education, telephone number, employment status, gravidity, and gestation weeks at enrollment). The structured questionnaire was completed by the participants.

\subsubsection{Pregnancy-relevant Health Behavior (PRHB) scale} The PRHB scale was used to evaluate the participant's adoption of the pregnancy-relevant healthy behaviors. It was developed by DeLuca and Lobel, $1995^{[14]}$ and adapted by Ickovics et al. $2007^{[7]}$ by taking 13 items from the original scale and adding a new created item (i.e., "drink at least 8 glasses of water a day"); as the original item that inquires about fluid intake was imprecise. The PRHB scale was used to express, how often in the past 2 weeks applicants had engaged in a variety of 14 health-related behaviors. This scale consists of 14 items categorized under three domains: exercise, sleep, and nutrition. First and second domains consist of 2 items each, while the third domain consists of 10 items. It was filled in by the participants and responses were based on a 5-point Likert scale ranges from $0=$ "never", 
1 = "almost never", 2 = "sometimes", 3 = "fairly often", to 4 = "very often". Non positive items (4, 6, 7, and 11), were reverse scored (e.g., how often did you eat fatty or oily food? or how often did you eat snack foods instead of a regular meal?). The total health behavior score ranges from 0 to 56 , with a higher score indicative of greater engagement in optimistic health practices.

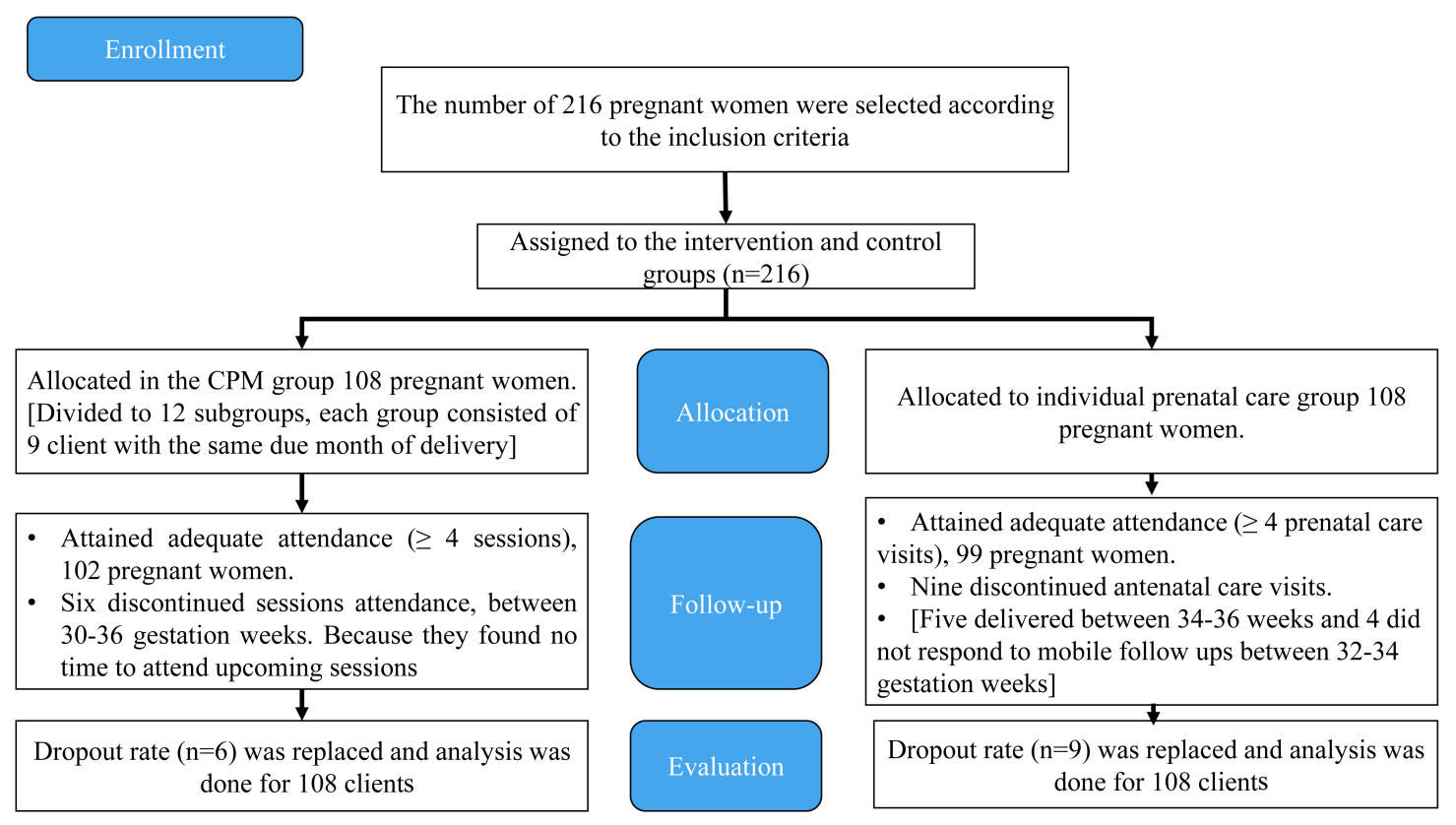

Figure 1. Flowchart of the study sample

\subsubsection{Pregnancy Symptom Distress (PSD) scale}

Extent of women's worrying from the pregnancy physical discomforts was assessed by adopting PSD scale. The scale was taken from the dictionary of measures for Centering Pregnancy Program. The dictionary was established by the academic staff of Yale University for a study funded by the National Health Institute. The scale is a selfadministered 14 items assesses how the pregnant women are worried or bothered about the common unpleasant physical symptoms experienced during pregnancy (e.g., nausea and vomiting, heartburn, frequent urination, fatigue, low back pain, vaginal discharge). Responses based on a 5-point Likert scale, with $0=$ "never", 1 = "rarely", 2 = "sometimes", 3 = "often" and 4 = "always". Total scale scores range from 0-56, higher scores indicative of higher distress from the unpleasant pregnancy symptoms.

\subsubsection{Patient Participation \& Satisfaction Questionnaire (PPSQ)}

Patient participation in and satisfaction with care were assessed by adopting the adapted version of PPSQ. The original scale was developed by Littlefield and Adams', ${ }^{[15]}$ and thereafter, Ickovics et al., ${ }^{[7]}$ added three items to 22 out of 23 items derived from the original questionnaire, two concerning women participation in care (i.e., "You were allowed to actively participate in your own care", and "You could voice your opinions about your care;") and one focused on satisfaction: "Overall, how satisfied were you with your prenatal care." The previously three items were developed by the Centering Pregnancy and Parenting Association. The PPSQ is a self-report measure with 25 items. Seventeen items focused on participant's satisfaction with the prenatal care givers and eight items focused on the woman's participation in care. Responses are based on a 5-point Likert scale ranges from 1 = "very dissatisfied", 2 = "fairly dissatisfied", 3 = "undecided; neither satisfied nor dissatisfied", 4 = "fairly satisfied", to 5 = "very satisfied". Total PPSQ score ranges from 25 to 125 with higher scores indicating greater satisfaction with and participation in prenatal care.

\subsubsection{Validity and reliability of the tools}

The three used tools in the present study were validated in previous studies. For this study, the Arabic translation was done according to the original questionnaires. Content validity of the Arabic version was confirmed by a panel of 5 experts in maternity nursing; before introducing it to the subjects. Validation was done to ensure that the questions were consistently conveyed and carry the intended meaning they were designed for. In this study, Cronbach alpha coefficients for internal consistency of the PRHB scale ranged from 80.2 to 82.2. For Pregnancy Symptoms Distress scale, Cronbach 
alpha coefficients ranged from 79.1 to 81.0 , while for the PPSQ, Cronbach alpha coefficients ranged from 81.9 to 83.8. The given values of Cronbach's alpha coefficients indicated accepted reliability for the tree tools.

\subsection{Ethical considerations}

An official approval was obtained from the board of Obstetrics and Gynecology Department of Mansoura University Hospital. The study was approved by the Ethics Committee of the Nursing Faculty. As well, pregnant women gave their informed consents before enrollment.

\subsection{Research process}

\subsubsection{The intervention group}

The intervention group received care according to the CPM of prenatal care. Such model of the prenatal care was carried out through three phases: preparation for the intervention, implementation of the intervention, and outcomes evaluation.

\section{Phase 1: Preparation for the intervention}

This phase included three steps: staff training, pilot study, and formation of the CPM subgroups.

\section{(1) Staff training}

To ensure success of the newly introduced model at Mansoura University Hospital, the research team members and support medical and nursing academic staff $(n=6)$ were subjected to 6 training sessions. The training sessions were implemented over three weeks. It was focused on learning the research team about approach of CPM implementation and revising the required clinical skills. By the end of training, the team conciliator assigned roles to each member. Medical staff was responsible about risk assessment through physical examination and nursing staff was responsible about education and skills building of the participants.

\section{(2) Pilot study}

After staff training and before implementing the CPM, a pilot study was conducted on $10 \%$ of the pre assigned sample size. Its aim was to assess clarity of the measures and acceptability of group prenatal care in real clinical field. According to piloting findings, the study measures were clear and no modifications were done. The CPM was acceptable from the pilot subjects. However, the most was not accepted performing the physical assessment at the group setting. Therefore, the researchers decided to perform physical assessment in an antenatal clinic, while the education and skills development were provided in a nearby room. The pilot sample was excluded from the analysed study sample.

\section{(3) Formation of the CPM subgroups}

At the initial prenatal care visit, the research team clarified Published by Sciedu Press study aim and nature to each eligible pregnant woman and female companions. Informed written consents were taken from the both, then each potential participant assigned to a CPM subgroup. Each CPM subgroup was consisted from 9 pregnant women shared due month of delivery. There was 12 subgroups belonged to the main CPM group. All members of same group were asked to attend as a group in upcoming visits. Participants attendance was based on predesigned prenatal care schedule of 10 structured sessions. The one session led over 90 to 120 minutes. Attendance of the companions was optional.

\section{Phase 2: Implementation of the intervention}

The implementation consisted of providing prenatal care through group structured sessions. Every session ran in an organized sequence. Each session started by risk assessment and followed by education and skills building (see Figure 2).

\section{(1) Risk assessment}

During the first 30-40 minutes of each session, physical assessment was done to all members of same group at one clinic. The physical assessment was carried out by a trained Junior Obstetrician. Thereafter, group members were asked to transfer to a nearby room to complete session's content (i.e., education and skills building). It was not applicable for the researchers to include physical examination, education, and skills development in the same room. Because Egyptian women were shame from being assessed in a group setting, even in a blocked off area. As well as, the antenatal clinics were not large enough to be divided into two parts, one for examination and another for education and skills building. To encourage participation in self-care, all participants were trained by a nurse researcher on how to weigh themselves, take blood pressure, and determine due date of delivery using the due date gestation wheel. In upcoming sessions, pregnant women participated actively in care by making such skills and recorded their findings on own charts and were allowed to discuss such findings with the leader's session.

\section{(2) Education}

Education was provided by conducting mother classes and skills building. Mother classes led by the research team nursing staff at the group setting and consumed 20 minutes per session. It touched certain themes related to pregnancy issues; such as the healthy behaviors that should be practiced during pregnancy, danger behaviors that carry harmful effects on mother or fetal health, optimal nutrition and exercise during pregnancy. Minor physical discomforts, danger signs need urgent consultation, preparation for childbirth, and postpartum matters such as postpartum blues and use of contraceptive methods were also discussed in mother classes. 


\begin{tabular}{|c|c|}
\hline \multicolumn{2}{|c|}{ Group Prenatal Care } \\
\hline \multicolumn{2}{|c|}{ Risk Assessment } \\
\hline \multicolumn{2}{|c|}{$\begin{array}{l}\text { Conducted by junior Obstetricians, through history taking and physical examination for each group member individually. } \\
\text { Members are actively engaged in self-care activities (e.g., weighing themselves and taking blood pressure). }\end{array}$} \\
\hline \multicolumn{2}{|c|}{ Education } \\
\hline Learning Sessions & Skills Building \\
\hline $\begin{array}{l}\text { Led by a nurse researcher and the support academic staff. It } \\
\text { was carried out within the group setting on pregnancy } \\
\text { related issues (e.g., proper nutrition or exercise). }\end{array}$ & $\begin{array}{l}\text { Led by a nurse researcher and the support academic staff, } \\
\text { within the group setting. It was conducted through } \\
\text { demonstration and re demonstration; on parenting skills } \\
\text { (e.g., baby bath, breast feeding, cord care, or diaper care). }\end{array}$ \\
\hline \multicolumn{2}{|c|}{ Group Discussions And Social Interaction } \\
\hline $\begin{array}{l}\text { The discussions were carried out between the same group me } \\
\text { guided by the research team members to ensure quality of the } \\
\text { The social support was emerged spontaneously, between the }\end{array}$ & $\begin{array}{l}\text { s and the guest speakers on pregnancy issues. It was } \\
\text { ided information. } \\
\text { group members themselves. }\end{array}$ \\
\hline
\end{tabular}

Figure 2. Intervention flowchart

\section{(3) Skills building}

To develop mother's parenting skills, a nurse researcher spent around 30 minutes from each session to demonstrate and allow the participants to re demonstrate certain skills. Simulated baby, abdomen, and perineum models were the used supportive materials. Skills building aimed to learn the participants how to provide self and baby care. It stressed on learning the mother how to breast feed, do a baby bath, umbilical cord care, care of episiotomy or Cesarean Section incision etc.

\section{Group discussions and social support}

Group discussions allowed between each subgroup members and knowledgeable guest speakers (i.e., female companions) at the group setting. It was guided by the group facilitator; nurse researcher or academic staff. Discussions targeted sharing experiences from others. Thirty minutes were assigned to carry out such discussions around pregnancy concerns of group members. Besides, leaflets included main minutes attentive on maternal-fetal and neonatal health were given to the intervention group.

Social support "The woman's self-perception of intimacy, opportunity for nurturance, and availability of informational, emotional, and material help", was a basic component in the CPM design. It was advanced spontaneously; by allowing the same group members to meet and interact over 10 structured sessions.

\section{Phase 3: Follow up and outcomes evaluation}

Phone numbers of the participants were taken for follow-up during the study period. The initial visit began before or at 24 weeks of gestation, the 2 nd visit was at 28th weeks, the after coming four visits were biweekly (i.e., at 30th, 32nd, 34th, and 36th week), while the last four visits were weekly (i.e., at 37th, 38th, 39th, and 40th week). The participant who did not attain adequate number of structured sessions attendance (i.e., four prenatal care visits) was declined from the study.

Outcomes of the intervention were assessed for the healthy behaviors adoption, mother's extent of worrying about pregnancy physical discomforts, and mother's satisfaction with and participation in prenatal care. First two outcomes were evaluated twice at baseline and after intervention, while the last one was assessed by the end of the study.

\subsubsection{The control group}

The control group received the conventional individual prenatal care. Such care involves individual meetings with a healthcare provider in duty. Each participant was subjected to examination within 5-10 minutes at maximum. There were no scheduled plans for the education or skill development issues. No chance to join her companion during the antenatal care visit.

\subsection{Limitations of the study}

The researchers faced two limitations in this study. The pregnancy-relevant healthy behaviors were evaluated by asking the participants to express "how often in the past 2 weeks 
applicant had engaged in a variety of 14 health-related behaviors"; indicating a lack of data about the other preceding period. However, it was not applicable to ask the woman to daily record behaviors engagement. Another limitation, is that the study was implemented at one institution and on healthy pregnant women; making the data difficult to be generalized.

\subsection{Data analysis}

All statistical analyses were performed using SPSS for windows version 20.0 (SPSS, Chicago, IL). Continuous data were expressed as mean $\pm S D$, while categorical data were expressed in number and percentage. The differences between two groups were determined using independent samples Student's $t$ test for variables with continuous data or chi-square test for variables containing categorical data. Statistical significance was set at $p<.05$.

\section{RESULTS}

\subsection{Demographic characteristics and homogeneity}

As presented in Table 1, a total of 216 pregnant women were enrolled in this study. Comparing the two groups, in- tervention and control, concerning demographic data and baseline characteristics both groups were homogeneous and no significant differences were observed $(p>.05)$.

\subsection{Effect of implementing the CPM on participants' adoption to PRHB}

Figure 3 illustrates that the total PRHB scores of the control and intervention groups at the beginning of the study were almost identical. Even though, after implementing the CPM total PRHB scores of the intervention group were significantly higher than that of the control group by 7.9 points $(37.71 \pm 2.91$ vs. $29.78 \pm 4.3$ respectively; $p<.001 \&$ $t=15.59$ ) (see Figure $3 \&$ Table 2). A comparison between the intervention and control groups' adoption of the PRHB sub-items at the pre and post intervention displayed in Table 2. This table reveals that there were no significant differences of the exercise, sleep and diet between the two groups at the beginning of the study ( $p=.115, .226, .860$ respectively). However, post intervention the PRHB sub-items (exercise, sleep and diet) of the intervention group were significantly higher than those of the control group by 4.08, 2.52, 1.3 points respectively; $p \leq .001$.

Table 1. Demographic data and baseline characteristics of the intervention and control groups $(\mathrm{N}=216)$

\begin{tabular}{|c|c|c|c|c|}
\hline \multirow{2}{*}{ Variable } & \multirow{2}{*}{$\begin{array}{l}\text { Intervention Group }(\mathrm{n}=108) \\
\mathrm{n} \% \text { or Mean } \pm S D\end{array}$} & \multirow{2}{*}{$\begin{array}{l}\text { Control group }(\mathrm{n}=108) \\
\mathrm{n} \% \text { or Mean } \pm S D\end{array}$} & \multicolumn{2}{|c|}{ Student's $t$ test } \\
\hline & & & $t$ & $p$ \\
\hline Mother's age (years) & $22.5 \pm 1.7$ & $22.4 \pm 1.8$ & 0.54 & .588 \\
\hline \multicolumn{5}{|l|}{ Employment status } \\
\hline Housewife & $54(50 \%)$ & $62(57.4 \%)$ & 1.19 & .275 \\
\hline Working & $54(50 \%)$ & $46(42.6 \%)$ & & \\
\hline \multicolumn{5}{|l|}{ Education level } \\
\hline Primary/preparatory & $45(41.7 \%)$ & $51(47.2 \%)$ & 0.67 & .411 \\
\hline Secondary/university & $63(58.3 \%)$ & $57(52.8 \%)$ & & \\
\hline \multicolumn{5}{|l|}{ Gravidity } \\
\hline Primigravida & $35(32.4 \%)$ & $37(34.3 \%)$ & 0.08 & \\
\hline Multigravida & $73(67.6 \%)$ & $71(65.7 \%)$ & 0.773 & \\
\hline Gestation weeks at enrollment & $18.2 \pm 3.8$ & $18.3 \pm 3.8$ & 0.16 & .873 \\
\hline
\end{tabular}

Table 2. Comparison between the intervention and control groups for the PRHB sub-items at the pre and post intervention $(\mathrm{N}=216)$

\begin{tabular}{|c|c|c|c|c|c|c|}
\hline \multirow{2}{*}{\multicolumn{2}{|c|}{ PRHB sub-items }} & \multirow{2}{*}{$\begin{array}{l}\text { Intervention Group }(\mathrm{n}=108) \\
\text { Mean } \pm S D\end{array}$} & \multirow{2}{*}{$\begin{array}{l}\text { Control Group }(\mathrm{n}=108) \\
\text { Mean } \pm S D\end{array}$} & \multirow{2}{*}{$\begin{array}{l}\text { Difference } \\
\text { Mean }\end{array}$} & \multicolumn{2}{|c|}{ Student's $t$ test } \\
\hline & & & & & $t$ & $p$ \\
\hline \multirow[t]{2}{*}{ Exercise } & Pre & $0.98 \pm 0.84$ & $0.81 \pm 0.79$ & 0.17 & 1.58 & .115 \\
\hline & Post & $6.05 \pm 0.72$ & $1.97 \pm 1.13$ & 4.08 & 39.39 & $<.001^{*}$ \\
\hline \multirow[t]{2}{*}{ Sleep } & Pre & $1.00 \pm 0.82$ & $1.14 \pm 0.86$ & 0.14 & 1.22 & .226 \\
\hline & Post & $7.01 \pm 0.70$ & $4.49 \pm 1.03$ & 2.52 & 21.02 & $<.001^{*}$ \\
\hline Diet & Pre & $12.54 \pm 2.4$ & $12.59 \pm 2.2$ & 0.05 & 0.18 & .860 \\
\hline \multicolumn{7}{|c|}{ Total PRHB score } \\
\hline & Pre & $14.52 \pm 2.7$ & $14.54 \pm 2.5$ & 0.02 & 0.05 & .958 \\
\hline & Post & $37.71 \pm 2.91$ & $29.78 \pm 4.3$ & 7.9 & 15.59 & $<.001^{*}$ \\
\hline
\end{tabular}

Note. ${ }^{*}$ High statistical significance 


\subsection{Effect of implementing the CPM on distress score} about pregnancy physical discomforts

Pre intervention the mean scores of distress in the intervention and control groups; as scored by PSD scale, were relatively identical $(27.8 \pm 2.1$ vs. $28.1 \pm 2.0$ respectively; $p=.296$ ). Post intervention mean distress scores of the intervention group was significantly lower than that of the control group by 7.4 points $(p<.001$, $t=16.89$, see Table 3 ).

\subsection{Effect of implementing the CPM on participants' participation and satisfaction total scores}

Table 4 illustrates that post intervention participants of the intervention group were more satisfied; according to the PPSQ, than those of the control group by a mean difference of 17.9 points $(80.8 \pm 10.4$ and $63.8 \pm 11.1$ respectively, $p<.001, t=11.62)$.

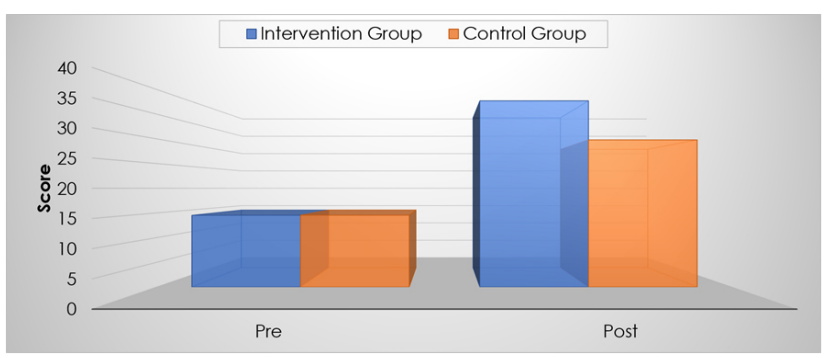

Figure 3. Comparison between the intervention and control groups for the PRHB total score at the pre and post intervention

Table 3. Comparison between the intervention and control groups regarding total physical discomfort distress scores at the pre and post intervention $(\mathrm{N}=216)$

\begin{tabular}{|c|c|c|c|c|c|}
\hline \multirow{2}{*}{ Distress score } & \multirow{2}{*}{$\begin{array}{l}\text { Intervention Group }(\mathrm{n}=108) \\
\text { Mean } \pm S D\end{array}$} & \multirow{2}{*}{$\begin{array}{l}\text { Control Group }(\mathrm{n}=108) \\
\text { Mean } \pm S D\end{array}$} & \multirow{2}{*}{$\begin{array}{l}\text { Difference } \\
\text { Mean }\end{array}$} & \multicolumn{2}{|c|}{ Student's $t$ test } \\
\hline & & & & $t$ & $p$ \\
\hline Pre & $27.8 \pm 2.1$ & $28.1 \pm 2.0$ & 0.3 & 1.05 & 0.296 \\
\hline Post & $8.06 \pm 2.40$ & $15.42 \pm 3.84$ & 7.4 & 16.89 & $<.001^{*}$ \\
\hline
\end{tabular}

Note. ${ }^{*}$ High statistical significance

Table 4. Comparison between the intervention and control groups regarding participation and satisfaction scores at post intervention $(\mathrm{N}=216)$

\begin{tabular}{|c|c|c|c|c|c|}
\hline \multirow{2}{*}{ Items } & \multirow{2}{*}{$\begin{array}{l}\text { Intervention Group }(\mathrm{n}=108) \\
\text { Mean } \pm S D\end{array}$} & \multirow{2}{*}{$\begin{array}{l}\text { Control Group }(\mathrm{n}=108) \\
\text { Mean } \pm S D\end{array}$} & \multirow{2}{*}{$\begin{array}{l}\text { Difference } \\
\text { Mean }\end{array}$} & \multicolumn{2}{|c|}{ Student's t test } \\
\hline & & & & $t$ & $p$ \\
\hline Satisfaction & $54.0 \pm 6.5$ & $43.5 \pm 7.0$ & 10.5 & 11.45 & .115 \\
\hline Participations & $26.7 \pm 4.2$ & $20.2 \pm 4.4$ & 6.05 & 11.12 & $<.001^{*}$ \\
\hline Total score & $80.8 \pm 10.4$ & $63.8 \pm 11.1$ & 17.9 & 11.62 & $<.001^{*}$ \\
\hline
\end{tabular}

Note. ${ }^{*}$ High statistical significance

\section{Discussion}

The present study aimed to compare effect of applying CPM versus individual prenatal care on certain prenatal care outcomes. This aim was achieved through the present study findings which revealed a significant difference in the pregnancyrelated health behaviors adoption scores between the CPM and individual prenatal care groups in favor to the CPM group. Therefore, the hypothesis "Pregnant women who receive care under the CPM, engage in pregnancy-relevant healthy behaviors more than those who receive individual prenatal care" was reinforced.

This finding is consistent with that of a quasi-experimental national study; conducted at two Maternal and Child Health centers in El Fayum City-Egypt. Such study aimed to evalu- ate adoption of healthy behaviors among two groups. One group involved 91 teenage pregnant women received CPM of prenatal care and another group of 108 received individual prenatal care. ${ }^{[16]}$ Such study found that the CPM group reported a significant increase in healthy behaviors adoption. Like consumption of balanced diet, maintaining exercise three times weekly, maintaining prenatal care appointments, read food and drug labels before use, and were more avoiding to risky sexual activities and excessively hot baths in comparison to individual prenatal care group.

Contrariwise, Hispanic study assessed upkeep of pregnancy related healthy behaviors in a smaller sample size $(n=49)$ and found that $87 \%$ to $97 \%$ consumed dairy products and maintained prenatal vitamins, $30 \%$ conserved eating healthy foods and 22\% kept exercising very often. ${ }^{[17]}$ However, find- 
ings were in favor to the conventional care group. Similarly, Baldwin (2006) evaluated the pregnant woman's perceived control of fetal health using fetal health locus of control instrument. Baldwin failed to support significant effect of centering pregnancy on fetal health locus of control. ${ }^{[18]}$ Authors of the both studies ${ }^{[17,18]}$ attributed the nonsignificant findings to three contributions; small sample size, non-randomization, and the ceiling effect (i.e., participants got high pretest scores on fetal health locus of control letting less room for improvement on posttest scores). Authors of the present study, endorsed the significant effect of CPM intervention on pregnancy-relevant healthy behaviors score to that the CPM operated as a means of sharing women's experiences and medical personnel information which contributed in conveying unhealthy behaviors to the healthier ones. Such chance closed the gap between what is Egyptian women need during pregnancy; compare notes with other pregnant women as pregnancy advances and sharing reactions with their buddies, and what is actually provided. The reason that may favor outcomes of CPM among Egyptian pregnant women.

Authors of the present study enquired each participant on "how much was she worried from 14 physical discomforts experienced during pregnancy". Participants of the CPM group reported lower distress scores than those of the individual prenatal care group. Thus, the second study hypothesis "Pregnant women who receive care under the CPM report lower distress score about the pregnancy physical discomforts than those who receive individual prenatal care" was supported. Present study investigators attributed such finding to sharing pregnancy experiences. Presenting experienced discomforts at the group setting giving opportunity to know its relief measures from the facilitator, accordingly complains and distress decreased. While the conventional care members did not get such chance of listening to complains of each other, rather their interactions were limited to the waiting room talks. To the best of our knowledge, this is the first study addressed the extent to which each pregnant mother was troubled about the pregnancy physical discomforts, so authors of the present study did not compare such finding with other findings.

In this study, higher participation and satisfaction scores were reported by the CPM group in comparison to the individual care group with a significant difference. Supporting the hypothesis "Pregnant women who receive care under the CPM report higher participation in and satisfaction with care scores in comparison to those who receive individual prenatal care".

A mean difference of statistically significant but of little clinical importance (4.9 points) was reported in a study ${ }^{[7]}$

Published by Sciedu Press assessed satisfaction with antenatal care models. Authors of such study, ${ }^{[7]}$ attributed the little mean difference of satisfaction score to the higher value of upper limit of questionnaire score. Likewise, Hispanic women received CPM expressed about their satisfaction with care by keep on contact with group members through phone conversations even after birth. Additionally $41 \%$ of women concluded that if had given the opportunity to select the model of care, they had to choose centering pregnancy. ${ }^{[17]}$

Higher satisfaction reported by the CPM group in the present study, may be related to the received benefit; particularly spending more time with health care providers and peers, receiving more information, sharing intimates experiences, sharing in their care, the given chance to join their companions during the sessions, and training on some required skills during the pregnancy period. However, Baldwin 2012 failed to notice a significant difference of the satisfaction and participation scores between the two groups; as it was found that both groups were satisfied with their prenatal model of care. Baldwin was ascribed lack of significant difference in participants' satisfaction to giving the participants a chance to be assigned selectively to a prenatal care model. ${ }^{[19]}$

Lack of social and psychological support, provided information, familial participation in care, and inadequate sharing information were the contributing factors for dissatisfaction with conventional antenatal care in a sample of 600 Egyptian pregnant women. ${ }^{[3]}$ Inadequate information provision resulted in a low satisfaction in a study compared Swedish and Australian women satisfaction with conventional antenatal care. ${ }^{[20]}$ Even with these evidences, conventional antenatal care remains the chief model in numerous republics. Centering Pregnancy is a model of prenatal care which gives the participants chance of experience exchange that is in turn building a self-efficacy about managing the experienced pregnancy discomforts, and complain less.

As an implication for nurses; who were the front-runner of childbirth classes for more than fifty years that were primarily advanced to prepare pregnant women for labor and delivery, CPM is the alternative of separate childbirth classes. It combines prenatal care and patient education in an inclusive design often led by maternity nurse facilitators. Nurses, with their proficient social and listening skills, function well within the group setting model of prenatal care.

\section{CONCLUSION AND RECOMMENDATIONS}

Based on the findings of the present study, hypotheses of the current study were accepted where CPM of prenatal care was associated with increased women adoption to the pregnancy-relevant healthy behaviors, reduced women dis- 
tress about the experienced pregnancy physical discomforts and increased women participation and satisfaction with prenatal care. Such findings stimulate the following recommendations:

(1) Concept of CPM should be disseminated and supported among healthcare providers at antenatal clinics.
(2) Future studies are recommended to address effect of introducing CPM on other prenatal outcomes; as mother's knowledge and readiness for labour and delivery.

\section{CONFlicts OF INTEREST Disclosure}

The authors declare they have no conflicts of interest.

\section{REFERENCES}

[1] Renfrew MJ, McFadden A, Bastos MH, et al. Midwifery and quality care: findings from a new evidence-informed framework for maternal and newborn care. The Lancet. 2014; 384(9948): 1129-45. https ://doi.org/10.1016/S0140-6736(14)60789-3

[2] Patil CL, Abrams ET, Klima C, et al. Centering Pregnancy-Africa: A pilot of group antenatal care to address Millennium Development Goals. Midwifery. 2013; 29(10): 1190-8. PMid: 23871278. https://doi.org/10.1016/j.midw.2013.05.008

[3] Montasser N, Helal RM, Megahed WM, et al. Egyptian Women's Satisfaction and Perception of Antenatal Care. International Journal of Tropical Disease and Health. 2012; 2(2): 145-56. PMid: 23205003. https://doi.org/10.9734/IJTDH/2012/1312

[4] Novick G, Sadler LS, Kennedy HP, et al. Women's experience of group prenatal care. Qualitative Health Research. 2011; 21(1): $97-$ 116. PMid: 20693516. https : //doi .org/10.1177/1049732310 378655

[5] Teate A, Leap N, Rising SS, et al. Women's experiences of group antenatal care in Australia - the Centering Pregnancy Pilot Study. Midwifery. 2011; 27(2): 138-45. PMid: 19386402. https://doi. org/10.1016/j.midw.2009.03.001

[6] Teate A, Leap N, Homer CSE. Midwives' experiences of becoming Centering Pregnancy facilitators: A pilot study in Sydney, Australia. Women and Birth. 2013; 26(1): e31-e6. PMid: 22926224. https://doi.org/10.1016/j.wombi.2012.08.002

[7] Ickovics JR, Kershaw TS, Westdahl C, et al. Group Prenatal Care and Perinatal Outcomes. a randomized controlled trial. Obstetrics \& Gynecology. 2007; 110(2 Pt 1): 330-9. PMid: 17666608. https://doi.org/10.1097/01.AOG.0000275284.24298.23

[8] Cunningham SD, Grilo S, Lewis JB, et al. Group Prenatal Care Attendance: Determinants and Relationship with Care Satisfaction. Maternal and Child Health Journal. 2017; 21(4): 770-6. PMid: 27485493. https://doi.org/10.1007/s10995-016-2161-3

[9] Magriples U, Boynton MH, Kershaw TS, et al. The impact of group prenatal care on pregnancy and postpartum weight trajectories. American Journal of Obstetrics and Gynecology. 2015; 213(5): 688.e1688.e9. PMid: 26164694. https://doi.org/10.1016/j.ajog .2015 .06 .066

[10] Ickovics JR, Earnshaw VA, Lewis JB, et al. Cluster Randomized Controlled Trial of Group Prenatal Care: Perinatal Outcomes Among
Adolescents in New York City Health Centers. American Journal of Public Health. 2016; 106(2): 359-65. PMid: 26691105. https://doi.org/10.2105/AJPH. 2015.302960

[11] Rising SS. Centering Pregnancy An interdisciplinary model of Empowerment. Journal of Nurse-Midwifery. 1998; 43(1): 46-54. https://doi .org/10.1016/S0091-2182(97)00117-1

[12] Lindgren KJ. Testing the Health Practices in Pregnancy Questionnaire-II. Journal of Obstetric, Gynecologic \& Neonatal Nursing. 2005; 34(4): 465-72. PMid: 16020414. https://doi.org/10.1 $177 / 0884217505276308$

[13] Jaykaran, Yadav P, Kantharia ND. Reporting of sample size and power in negative clinical trials published in Indian medical journals. Journal of Pharmaceutical Negative Results. 2011; 2(2): 87-90. https ://doi .org/10.4103/0976-9234.90220

[14] Deluca RS, Lobel M. Conception, commitment, and health behavior practices in medically high-risk pregnant women. Women's Health: Research on Gender, Behavior, and Policy. 1995; 1(3): 257-71.

[15] Littlefield VM, Adams BN. Patient participation in alternative perinatal care: Impact on satisfaction and health locus of control. Research in Nursing \& Health. 1987; 10(3): 139-48. https ://doi .org/10 .1002 /nur . 4770100305

[16] Farrag R, Farag F. Centering model versus Traditional Prenatal Care for enhancing healthy practice among rural teenage pregnancy. The 7th International Scientific Nursing Conference 2015 "Evolution of Nursing: A Pathway to Excellence”. 20-21st April 2015.

[17] Robertson B, Aycock DM, Darnell LA. Comparison of Centering Pregnancy to Traditional Care in Hispanic Mothers. Maternal and Child Health Journal. 2009; 13(3): 407-14. PMid: 18465216. https ://doi.org/10.1007/s10995-008-0353-1

[18] Baldwin KA. Comparison of selected outcomes of CenteringPregnancy versus traditional prenatal care. Journal of Midwifery \& Women's Health. 2006; 51(4): 266-72. PMid: 16814221. https : //doi.org/10.1016/j.jmwh.2005.11.011

[19] Baldwin K, Phillips G. Voices Along the Journey: Midwives' Perceptions of Implementing the CenteringPregnancy Model of Prenatal Care. The Journal of Perinatal Education. 2011; 20(4): 210-7. PMid: 22942623. https://doi.org/10.1891/1058-1243.20.4.210

[20] Hildingsson I, Haines H, Cross M, et al. Women's satisfaction with antenatal care: comparing women in Sweden and Australia. Women and Birth. 2013 Mar; 26(1): e9-e14. PMid: 22795867. https://doi.org/10.1016/j.wombi.2012.06.002 